\title{
Investors' Expertise, Personality Traits and Susceptibility to Behavioral Biases in the Decision Making Process
}

\author{
Marcin Rzeszutek', Adam Szyszka², Monika Czerwonka ${ }^{3}$
}

\begin{abstract}
The aim of this paper is to investigate the degree of susceptibility to behavioral biases (the certainty effect, the sunk cost fallacy, and mental accounting) among people of various levels of expertise in market investments and to determine whether this susceptibility is correlated with certain personality traits (impulsivity, venturesomeness, and empathy). The study included 200 participants: 100 retail investors who regularly invest in the Warsaw Stock Exchange and 100 students of the Warsaw School of Economics who are casually involved in investing. In this study, employing a survey methodology, we conducted a laboratory experiment that allowed us to isolate behavioral biases and personality traits and measure their influence on investors' decision-making processes. The participants filled out questionnaires containing two parts: 1) three situational exercises, which assessed susceptibility to behavioral biases, and 2) the Impulsivity, Venturesomeness, Empathy Questionnaire (IVE) Questionnaire which measures three personality traits (impulsivity, venturesomeness, and empathy). Statistical analyses demonstrated that susceptibility to behavioral biases depends on the level of expertise in market investing such that expertise increases susceptibility to behavioral biases. Some personality traits influenced the participants' likelihood of displaying these biases.
\end{abstract}

KEY WORDS: $\quad$ investors' expertise; personality traits; behavioral biases; rationality; behavioral finance

JEL Classification: G19

${ }^{1}$ University of Finance and Management - Faculty of Management and Finance, Warsaw, Poland; ${ }^{2}$ Warsaw School of Economics - Department of Capital Markets, Poland; ${ }^{3}$ Warsaw School of Economics - Department of Finance, Poland

\section{Introduction}

There is a vast literature dedicated to showing that neoclassical finance theory does not properly depict the real behavior of an investor in a stock market and that the investment decision-making process is greatly shaped by psychological factors, such as moods, emotions and

Correspondence concerning this article should be addressed to: Marcin Rzeszutek, University of Finance and Management Faculty of Management and Finance, Pawia 55, 01-030 Warsaw, Poland. T: +48 2253654 11. E-mail: rzeszutek@vizja.pl personality traits (Akerlof \& Schiller, 2009; De Bondt \& Thaler, 1987; Kahneman 2012; Szyszka \& Zielonka, 2007; Todd \& Gigerenzer, 2003). Abundant evidence from psychological research that suggests that humans have restrained cognitive possibilities, are controlled by emotions, and succumb to mob mentality while making choices in risky and uncertain situations, drew financial behaviorists' attention to the drawbacks of the homo economicus assumption and the hypothesis about the market's efficiency (Fama, 1970; 1991; Markowitz, 1952; Von Neumann \& Morgenstern, 1944) and the suscepti- 
bility of investors to so-called behavioral biases resulting from cognitive biases and heuristics as well as emotions (Agnew, 2006). These biases disrupt the rationality of the process of making investment decisions and contribute to inefficient market reactions to information and, as a result, to asset mispricing (Coval \& Shumway, 2005; Rzeszutek \& Czerwonka, 2011). Szyszka (2010) proposed the Generalized Behavioral Asset Pricing Model, which shows how asset prices can be influenced by various behavioral biases and how prices may deviate from fundamental values due to investors' irrational behavior. The model distinguishes three behavioral variables that are linked to errors in understanding and transforming information signals, problems with representativeness and probability judgment, and unstable preferences. In this paper, we investigate three examples of behavioral phenomena that are captured by this model: the certainty effect, the sunk-cost fallacy, and mental accounting. In particular, we look at how these three important behavioral phenomena manifest among investors depending on their level of expertise and personality traits, such as impulsivity, venturesomeness, and empathy.

\subsection{Certainty Effect}

Daniel Kahneman and Amos Tversky noted many anomalies in how individual preferences are shaped in situations of uncertainty and risk (1973; 1979; 1984). One such anomaly is the certainty effect: the tendency to overweight outcomes that are certain compared with outcomes that are highly probable. For example, Kahneman (2012) observed that a substantial majority of participants prefer a certainty of winning $\$ 850$ to a $90 \%$ probability of winning $\$ 1,000$, although the expected value of the latter option is actually higher. Overweighting a certain win over a highly probable option, as in the example above, prompts people to choose an option with a lower expected value. Therefore, the certainty effect was shown to lead to potentially less profitable investment decisions in the capital market (Agnew, 2006).

\subsection{Sunk-Cost Fallacy}

Making decisions in conditions of risk and uncertainty is also dependent on the sunk cost fallacy, which describes the influence of costs incurred in the past on future investment decisions (Arkes \& Blumer,
1985). According to neoclassical finance theory, only an analysis of current and future losses and profits should influence these decisions (Bernstein, 2007). However, investors all too often attach importance to outlays made in the past toward a given investment, and these past costs significantly influence both present and future decisions (De Bondt \& Makhija, 1988). On the stock market, this overweighting of past costs often leads to retaining positions that generate costs for too long and sometimes even to purchasing more shares after declines (Friedman et al., 2007). In doing so, investors seek to reduce the average price of purchasing a share in the hopes that they will be able to record profits more quickly after a small economic upturn (Connolly \& Zeelenberg, 2002; McAfee, Mialon, \& Mialon, 2010).

\subsection{Mental Accounting}

Mental accounting is a process of mentally coding, categorizing, and evaluating cash flow, i.e., recording particular expenditures and revenues in various mental accounts (Thaler, 1999). The mental accounting effect undermines the principle of substitutability, which claims that money has no label, i.e., that the source of funds is irrelevant in the spending of them (Haigh \& List, 2005). Stock market investors do not follow this principle but rather display mental accounting and treat profits attained as dividends (cash) differently from identical "paper" profits-those resulting from an increased exchange rate (Winnett \& Lewis, 1994). It has also been observed that investors are incapable of closing losing positions and investing funds from those losing shares in new endeavors because these shares are treated as a separate mental account (Odean, 1998). Instead, many hope for changing trends to make up for those losses in the future, which leads to a progressive reduction in the worth of their investment portfolio.

\subsection{Expertise and Rationality in Decision Making}

Expertise or professional experience sometimes helps in making good decisions; however, equally often experts, aware of their knowledge within a given domain, can fall prey to various behavioral biases, sometimes even more so than naïve individuals (Braun \& Yaniv, 1992; Krems \& Zierer, 1994). Researchers have ana- 
lyzed susceptibility to cognitive and emotional biases among professional investors compared with individuals who engage in the capital market on a more casual basis or even compared with complete novices (e.g., Camerer \& Johnson, 1997; Tyszka \& Zielonka, 2002). The results of these studies show that extensive experience in stock market investing does not protect people from behavioral biases. Professional investors are particularly vulnerable to divergence from rational action if a task is not transparent and there are no univocal indicators suggesting an appropriate solution (Garvey \& Murphy, 2008). In these cases, professionals often fall back onto schemas and/or heuristics. What is surprising is that, after making the wrong decision, even as new information arises that clarifies the problem, professional investors can become more convinced of having a good understanding of the issue and do not change their initial stance (Verma, Baklaci \& Soydemir, 2008). This conviction that they are right grows, despite an influx of information indicating their error in judgment.

\subsection{Personality Traits and Susceptibility to Behavioral Biases among Stock Market Investors}

Recent studies in behavioral finance incorporate personality into the analysis of investors' behavior to seek a deeper understanding of investors' decision-making processes and their performances in the stock market (Borghans et al., 2008; Jadlow \& Mowen, 2010). In particular, it has been observed that certain personality traits can influence investors' preferences (Chira, Adams \& Thornton, 2008), risk attitudes (Mishra, Lalumiere \& Williams, 2010) and investment choices and outcomes (Belcher, 2010; Pompian \& Longo, 2004). Therefore, some authors state that individual differences in personality traits among investors can explain their susceptibility to various behavioral biases in the stock market investment process (Mayfield, Perdue \& Wooten, 2008). For example, Durand, Newby \& Sanghani, (2008) showed the positive relationship between extraversion and agreeableness from the Big Five personality traits (openness, conscientiousness, extraversion, agreeableness and neuroticism; Costa \& McCrae, 1985) and the susceptibility to disposition effect and overconfidence among Australian investors. Additionally, it has been observed that neuroticism from the Big Five is positively correlated with a propensity toward the sunk cost fallacy among Tehran investors (Sadi et al., 2011). Baddeley et al. (2010) also found an association between particular Eysenck's (1978) personality traits (impulsivity, venturesomeness and empathy) and susceptibility to social influence in financial decision making (herding) among British investors. From the abovementioned personality traits, impulsivity was negatively linked to the degree of hyperbolic discounting and the level of risk aversion in another study conducted on British investors (Borghans et al., 2008). Finally, impulsivity was also found to be a significant predictor of pathological gambling behavior (Alessi \& Petry, 2003). Although exploring investors' personality traits seems to be a new and inspiring way to understand how investment decisions are made, there has not yet been a sufficient number of studies on this topic.

\subsection{Purpose and Hypotheses}

The first aim of this research is to investigate the degree of susceptibility to behavioral biases (the certainty effect, the sunk cost fallacy, and mental accounting) among people with various levels of expertise in investing, i.e., frequent retail investors at the Warsaw Stock Exchange (see further: investors) and casual investors (students of the Warsaw School of Economics; see further: students). A second goal of this research is to determine whether this susceptibility is correlated with certain personality traits (impulsivity, venturesomeness, and empathy). Because there is still a lack of data studies in behavioral finance literature investigating the issues noted in this article (or the existing results in behavioral finance literature are ambiguous), we treated our study as exploratory. Therefore, the following hypotheses were tested:

1. The degree of susceptibility to behavioral biases (see: certainty effect, sunk-cost fallacy and mental accounting) in decision making varies depending on an individual's amount of expertise in stock market investing.

2. Susceptibility to behavioral biases (see: certainty effect, sunk-cost fallacy and mental accounting) in decision making will be correlated with certain personality traits (impulsivity, venturesomeness, and empathy) in all participants. 


\section{Method}

\subsection{Participants and Procedure}

This study was conducted on a convenience sample, with the subjects selected because they were available, and the researchers did not consider selecting subjects as representative of the entire population of investors in Poland (Freedman, 2009). Two hundred participants represented two 100-person groups, which differed in their level of expertise in stock market investing. The first group was made up of 100 retail investors frequently investing at the Warsaw Stock Exchange. These participants were recruited from among attendees of a conference organized by the Association of Individual Investors and from among trainees of advanced workshops organized by PERK, an organization that provides education about capital markets in Warsaw. The second group was made up of 100 students of the Warsaw School of Economics. These students had casual experience investing in the stock market and planned to pursue careers connected to the stock exchange. Basic demographic information and information about the level of stock market expertise is presented in Table 1 .

As seen in Table 1, the study sample had similar gender distribution across the two subgroups of participants. The average age of the stock market investors was 33.19 years $(S D=10.09)$ and among the WSE students, the average age was 21.62 years $(S D=1.89)$. Among the stock market investors, 96 had completed tertiary education and 4 had obtained PhDs. Among the WSE students, 78 had completed secondary education and 22 had obtained MAs or BAs in economics. The average number of years of investing on the Warsaw Stock Exchange was $6.56(S D=1.95)$ among investors and $1.76(S D=1.64)$ among students. Finally, the average value of the stock portfolio (PLN) among investors was 1,49300 PLN ( $S D=2,27796.89$ ), and it was 1,0450 PLN ( $S D=1,5326.33)$ among students.

In this study, in which a survey methodology was employed, we conducted a laboratory experiment that allowed us to isolate behavioral biases and personality traits and measure their influence on investors' decision-making processes. The questionnaires were in hard copy form and were delivered to the participants in person so that they could also be informed about the anonymity of individual results and all other necessary details. The participants filled out the surveys in Polish, and the total distribution study response rate was approximately $65 \%$.

\subsection{Materials}

The study questionnaire contained two parts. First, the participants completed a form featuring three situational scenarios (see, Appendix), in which they had to choose how they would behave in a hypothetical situation when faced with a number of options. In each scenario, susceptibility to the behavioral biases noted in the hypotheses was assessed. These scenarios have been used in classical studies on decision making. In the first scenario, adapted from Kahneman \& Tversky (1979), propensity toward the certainty effect was measured. The second scenario, adapted from Thaler (1999), checked susceptibility to mental accounting. The last scenario, adapted from Arkes and Blumer (1985), measured propensity toward the sunk cost fallacy. The questionnaire also asked about the abovementioned demographics, including age, gender, education and investing expertise.

In the second part of the questionnaire, the participants completed the IVE Questionnaire (Impulsivity, Venturesomeness, Empathy Questionnaire; Eysenck \& Eysenck, 2006). This tool is used to measure three personality traits: impulsivity, venturesomeness, and empathy. Impulsivity is defined as the pathological aspect of risk-taking behavior and indicates a very strong tendency to undertake risky, unplanned activities, to make quick decision and to have rash reactions. It is primarily manifested in problems with self-control and the inability to delay gratification. Venturesomeness measures not only readiness to undertake risky behaviors but also self-confidence, self-efficacy, persistence in goal pursuit, and novelty seeking. Although this trait is similar to impulsivity, the two traits differ in that impulsive people take risks without considering the consequences of their actions, whereas venturesome people seek out challenges and take risks, all the while taking into account the possible consequences of their actions. Finally, empathy is the ability to perceive, understand and react to others' emotions and take on others' emotional perspectives (Eysenck \& Eysenck, 1978). The IVE comprises 54 items in the form of questions with yes/no answers. Final scores are calculated by totaling the "yes" answers to the items 
Table 1. Participants' basic demographic information and stock market investment expertise

\begin{tabular}{|c|c|c|c|c|c|}
\hline Group & Gender & Age & Education & $\begin{array}{c}\text { Years investing in the } \\
\text { stock market }\end{array}$ & $\begin{array}{l}\text { Value of stock } \\
\text { portfolio (PLN) }\end{array}$ \\
\hline \multirow{5}{*}{$\begin{array}{l}\text { 1. Stock } \\
\text { market } \\
\text { investors } \\
(n=100)\end{array}$} & Men & $M=33.19$ & Primary $=0$ & $M=6.56$ & \\
\hline & 53 & $S D=10.09$ & Secondary $=0$ & $S D=1.95$ & $M=1,49300.00$ \\
\hline & Women & Range & Tertiary $(\mathrm{MA}$ or $\mathrm{BA})=96$ & Minimum $=2$ & $S D=2,27796.89$ \\
\hline & 47 & $28-62$ & $\mathrm{PhD}=4$ & Maximum $=27$ & \\
\hline & Men & $M=21.62$ & Primary $=0$ & $M=1.76$ & \\
\hline \multirow{3}{*}{$\begin{array}{l}\text { 2. Students } \\
(\mathrm{n}=100)\end{array}$} & 52 & $S D=1.89$ & Secondary $=78$ & $S D=1.64$ & $M=1,0450.00$ \\
\hline & Women & Range & Tertiary $(\mathrm{MA}$ or $\mathrm{BA})=22$ & Minimum $=0$ & $S D=1,5326.33$ \\
\hline & 48 & $18-30$ & $\mathrm{PhD}=0$ & Maximum $=4$ & \\
\hline
\end{tabular}

(some are reverse-scored) on three subscales: impulsivity, venturesomeness, and empathy. The reliability coefficients for the three IVE subscales range from $\alpha=.76$ to $\alpha=.0 .81$ (Eysenck \& Eysenck, 2006). The reliability coefficients for the subscales in this study were $\alpha=.79$ for impulsivity, $\alpha=.78$ for venturesomeness, and $\alpha=.72$ for empathy.

\section{Results}

Statistical analyses were conducted using PASW Statistics 18 . To test the first hypothesis concerning the link between investing expertise and the degree or rationality of decision making as measured through the three behavioral biases contained in the exercises, a series of chi $^{2}$ tests of the independence of two variables were conducted. Three comparisons were made. In each, one variable was the group of participants (investors or students); the other variable was making a rational or irrational decision in each of the three exercises (see: Appendix). For a rational answer (one that showed no behavioral bias), a participant received 1 point. For an irrational answer (one that showed the bias), the participant received no points. For example, the first exercise in the questionnaire measured susceptibility to the certainty effect. Option A was considered the rational answer in the first part of the exercise; option $\mathrm{C}$ was considered rational in the second part (see: Appendix). These options had the greatest expected value. Therefore, a subject received 1 point for this exercise if he/she circled both $\mathrm{A}$ and $\mathrm{C}$ and 0 points otherwise. The other choices had lower expected values; as a re- sult, they were coded as irrational in accordance with Kahneman and Tversky's study (1979).

To assess whether the investors differed from the students with regard to susceptibility to the certainty effect, a chi ${ }^{2}$ test of the independence of the two variables was performed. The results are shown in Table 2. The frequencies of rational answers by investors versus students were compared, showing relative susceptibility to the certainty effect.

A significant chi $^{2}$ result allows us to reject the null hypothesis about the independence of the two variables and accept the alternative hypothesis, that the two variables are somehow related. In the case of the certainty effect, the group of students behaved significantly more rationally (39 rational answers) than the group of investors (26 rational answers), $\operatorname{chi}^{2}(1, N=200)=3.85 ; p<.05$. The investors, thus, were shown to be more susceptible to the certainty effect than the students.

The same analysis was performed to investigate whether the investors differed from the students with regard to susceptibility to the sunk cost fallacy. The results are shown in Table 3.

In the case of the sunk cost fallacy, the difference in answers measuring susceptibility to the sunk cost fallacy between the investors and students was not significant, $\operatorname{chi}^{2}(1, N=200)=.10 ; n s$.

An identical analysis was performed to determine whether the investors differed from the students with regard to susceptibility to mental accounting. The results are shown in Table 4. 
Table 2. Outcome of chi ${ }^{2}$ test for frequency of rational answers of stock market investors and WSE students in the exercise measuring susceptibility to the certainty effect

\begin{tabular}{lccccc}
\hline $\begin{array}{l}\text { The certainty } \\
\text { effect }\end{array}$ & $\begin{array}{c}\text { Stock market } \\
\text { investors }\end{array}$ & WSE students & Chi $^{2}$ & df & $p$ \\
\cline { 2 - 6 } & 26 & 39 & 3.85 & 1 & .041 \\
\hline
\end{tabular}

Table 3. Outcome of $\mathrm{chi}^{2}$ test for frequency of rational answers of stock market investors and WSE students in the exercise measuring susceptibility to the sunk cost fallacy

\begin{tabular}{lccccc}
\hline \multirow{2}{*}{$\begin{array}{l}\text { The sunk cost } \\
\text { fallacy }\end{array}$} & $\begin{array}{c}\text { Stock market } \\
\text { investors }\end{array}$ & WSE students & Chi $^{2}$ & df & $p$ \\
\cline { 2 - 6 } & 31 & 29 & .10 & 1 & .762 \\
\hline
\end{tabular}

Table 4. Outcome of chi $^{2}$ test for frequency of rational answers of stock market investors and WSE students in the exercise measuring susceptibility to mental accounting

\begin{tabular}{lccccc}
\hline \multirow{2}{*}{$\begin{array}{l}\text { Mental } \\
\text { accounting }\end{array}$} & $\begin{array}{c}\text { Stock market } \\
\text { investors }\end{array}$ & WSE students & Chi $^{\mathbf{2}}$ & df & $\boldsymbol{p}$ \\
\cline { 2 - 6 } & 40 & 53 & 3.40 & 1 & .061 \\
\hline
\end{tabular}

Table 5. Means and standard deviations for personality traits among stock market investors and students $(N=200)$

\begin{tabular}{|c|c|c|c|c|c|}
\hline & \multicolumn{2}{|c|}{$\begin{array}{l}\text { Stock market investors } \\
\qquad(\mathrm{n}=100)\end{array}$} & \multicolumn{2}{|c|}{$\begin{array}{l}\text { WSE students } \\
\quad(n=100)\end{array}$} & \multirow{2}{*}{$\begin{array}{c}\text { t-test comparing } \\
\text { investors to students }\end{array}$} \\
\hline & $M$ & $S D$ & $M$ & $S D$ & \\
\hline Impulsivity & 7,55 & 3,60 & 8,45 & 3,41 & $-1,82 \#$ \\
\hline Venturesomeness & 9,15 & 3,24 & 10,06 & 3,14 & $-2,01^{*}$ \\
\hline Empathy & 11,06 & 3,77 & 11,59 & 3,55 & $-1,02$ \\
\hline
\end{tabular}

Note: $\# p<.10 ;{ }^{*} p<.05$.

In the case of mental accounting, we observed a trend towards statistical significance, chi $^{2}(1, N=200)=.061$. The students' group (53 rational answers) behaved in a more rational way than the investors (40 rational answers).

In the next stage of statistical analyses, we sought to check whether the two groups of participants differed from each other within the level of personality traits. A t-test for independent groups was conducted. The results are presented in Table 5, which shows means and standard deviations for personality traits among the stock market investors and students. We performed a suitable analysis in regard to gender; however, no statistically significant differences were found. 
As shown in Table 5, the students were significantly more venturesome and marginally more impulsive than the investors. The two groups did not differ in their levels of empathy.

To test the second hypothesis, logistic regression analyses were conducted. Susceptibility to behavioral biases was the outcome variable. Personality traits (impulsivity, venturesomeness, and empathy) were the predictor variables. We note that logistic regression is the method of choice for analyzing results of studies in which the dependent variable is dichotomous while the independent variables are interval or categorical (Freedman, 2009). This was the case in our study. It is possible to make use of discriminant analysis in these cases; however, it was found that logistic regression outperforms discriminant analysis for non-normal classification problems, which was also the case in our study. Additionally, while ordinary regression uses ordinary least squares to search for a best fitting line and addresses coefficients that predict the change in the outcome variable for one unit change in the predictor variable, logistic regression estimates the probability of an event occurring (Freedman, 2009). Furthermore, while in linear regression, the relationship between the outcome and the predictor variables is linear; this assumption is not made in logistic regression. Taking the abovementioned factors into account, in our study, we used this statistical method because the outcome variable was categorical (see: making a rational or irrational decision in each of the three exercises) and the predictor variables were continuous (see: personality traits). Finally, we emphasize that the participants' age and other demographics (gender, education) were not statistically significant variables in our model; consequently, we did not control for them in our analyses. Three analyses were performed, one for each of the exercises in the questionnaire. The results are shown in Tables 6, 7, and 8.

The results shown in Table 6 indicate that there was no significant relationship between impulsivity or empathy and susceptibility to the certainty effect in our sample as a whole (respectively, $p=.967$ and $p=.14$ ). There was, however, a significant relationship between venturesomeness and susceptibility to the certainty effect $(p<.05)$. Specifically, the more venturesome a participant was, the more likely he was to give a rational answer $(\operatorname{Exp}(B)>1)$ and thus, the lower his suscepti- bility to the certainty effect. We can accurately predict rational answers to the certainty effect exercise based on level of venturesomeness in $72 \%$ of our cases.

The results shown in Table 7 indicate that there is no relationship between impulsivity or empathy and susceptibility to the sunk cost fallacy in our sample (respectively, $p=.434$ and $p=.480$ ). There was a significant relationship between venturesomeness $(p<.05)$ and susceptibility to the sunk cost fallacy. Specifically, the more venturesome one was, the more likely he was to give a rational answer in the sunk cost exercise (Exp $(B)>1)$. We can accurately predict rational answers in the sunk cost exercise based on venturesomeness in $74 \%$ of our cases.

The results in Table 8 show that there was no relationship between impulsivity or empathy and tendency to mental accounting in our sample ( $p=.620$ and $p=.668$, respectively). There was, however, a relationship between venturesomeness $(p<.001)$ and susceptibility to mental accounting. Specifically, greater venturesomeness was linked to a lower susceptibility to mental accounting when making decisions ( $\operatorname{Exp}(\mathrm{B})>1)$. On the basis of venturesomeness levels, we can predict rational answers in the mental accounting exercise in $62 \%$ of our cases.

To verify whether the relationship between venturesomeness and susceptibility to the studied behavioral biases was identical or different in the two groups of participants, we conducted a logistic regression in which the predictors were the particular group of participants, venturesomeness, and the interaction between these two variables. In other words, membership in one of the two participant groups was treated as a moderator of the relationship between venturesomeness and the probability of making rational decisions in the three exercises.

The results shown in Table 9 indicate that the interaction between group and venturesomeness was not significant; thus, group belonging did not moderate the relationship between venturesomeness and making rational decisions.

To verify whether the relationship between impulsivity and susceptibility with the studied behavioral biases was identical or different in the two groups of participants, we conducted a logistic regression in which the predictors were the particular group of participants, impulsivity, and the interaction between these two vari- 
Table 6. Logistic regression analysis with personality traits as predictors of susceptibility to the certainty effect in the sample as a whole $(\mathrm{N}=200)$

\begin{tabular}{lccccc}
\hline Personality traits & B & Exp (B) & Wald & df & p \\
\hline Impulsivity & -.03 & .97 & .56 & 1 & 1 \\
Venturesomeness & .11 & 1.11 & 4.01 & 1 & .041 \\
Empathy & -.07 & .94 & 2.21 & 1 & .14 \\
\hline
\end{tabular}

Table 7. Logistic regression analysis with personality traits as predictors of susceptibility to the sunk cost fallacy in the sample as a whole $(\mathrm{N}=200)$

\begin{tabular}{lccccc}
\hline Personality traits & B & Exp (B) & Wald & df & $p$ \\
\hline Impulsivity & -.04 & .96 & .61 & 1 & 1 \\
Venturesomeness & .12 & 1.12 & 4.56 & 1 & .032 \\
Empathy & -.03 & .97 & .48 & 1 & .480 \\
\hline
\end{tabular}

Table 8. Logistic regression analysis with personality traits as predictors of susceptibility to mental accounting in the sample as a whole $(\mathrm{N}=200)$

\begin{tabular}{lccccc}
\hline Personality traits & B & Exp (B) & Wald & df & p \\
\hline Impulsivity & -.02 & .98 & .25 & 1 & .620 \\
Venturesomeness & .20 & 1.22 & 14.28 & 1 & .001 \\
Empathy & -.01 & 1.02 & .18 & 1 & .668 \\
\hline
\end{tabular}

ables. In other words, membership in one of the two participant groups was treated as a moderator of the relationship between impulsivity and the probability of making rational decisions in the three exercises.

The results shown in Table 10 indicate that the interaction between group and impulsivity was not significant; thus, group belonging did not moderate the relationship between impulsivity and making rational decisions.

To verify whether the relationship of empathy and susceptibility to the studied behavioral biases was identical or different in the two groups of participants, we conducted a logistic regression in which the predictors were the particular group of participants, empathy, and the interaction between these two variables. In other words, membership in one of the two participant groups was treated as a moderator of the relationship between empathy and the probability of making rational decisions in the three exercises.

The results shown in Table 11 indicate that the interaction between group and empathy was not significant; thus, group belonging did not moderate the relationship between empathy and making rational decisions. 
Table 9. Analysis of interaction in logistic regression, where group (stock market investors vs. WSE students) is a moderator of the relationship between venturesomeness and likelihood of making a rational decision in each of the three exercises

\begin{tabular}{|c|c|c|c|c|c|}
\hline & B & $\operatorname{Exp}(B)$ & Wald & df & $p$ \\
\hline $\begin{array}{c}\text { The certainty effect } \\
\text { Group xV }\end{array}$ & -.01 & .99 & .01 & 1 & .940 \\
\hline $\begin{array}{c}\text { The sunk cost fallacy } \\
\text { Group } \times V\end{array}$ & .13 & 1.14 & 1.44 & 1 & .230 \\
\hline $\begin{array}{c}\text { Mental accounting } \\
\text { Group xV }\end{array}$ & -.06 & .94 & .40 & 1 & .528 \\
\hline
\end{tabular}

Note: $V$ - venturesomeness; B - unstandardized regression coefficient; Exp(B) - standardized regression coefficient; Wald Wald test result; $\mathrm{df}$ - degrees of freedom; $p$ - statistical significance.

Table 10. Analysis of interaction in logistic regression, where group (stock market investors vs. WSE students) is a moderator of the relationship between impulsivity and likelihood of making a rational decision in each of the three exercises

\begin{tabular}{|c|c|c|c|c|c|}
\hline & B & $\operatorname{Exp}(B)$ & Wald & df & $p$ \\
\hline $\begin{array}{c}\text { The certainty effect } \\
\text { Group x I }\end{array}$ & -.17 & .84 & 3.60 & 1 & .068 \\
\hline $\begin{array}{l}\text { The sunk cost fallacy } \\
\text { Group x I }\end{array}$ & .01 & 1.01 & .02 & 1 & .875 \\
\hline $\begin{array}{c}\text { Mental accounting } \\
\text { Group x I }\end{array}$ & .03 & 1.03 & .13 & 1 & .723 \\
\hline
\end{tabular}

Note: I - impulsivity; B - unstandardized regression coefficient; Exp(B) - standardized regression coefficient; Wald - Wald test result; $\mathrm{df}$ - degrees of freedom; $p$ - statistical significance.

Table 11. Analysis of interaction in logistic regression, where group (stock market investors vs. WSE students) is a moderator of the relationship between empathy and likelihood of making a rational decision in each of the three exercises

\begin{tabular}{|c|c|c|c|c|c|}
\hline & B & $\operatorname{Exp}(B)$ & Wald & df & $p$ \\
\hline $\begin{array}{c}\text { The certainty effect } \\
\text { Group xE }\end{array}$ & -.05 & .95 & .40 & 1 & .529 \\
\hline $\begin{array}{l}\text { The sunk cost fallacy } \\
\text { Group x E }\end{array}$ & -.06 & .94 & .46 & 1 & .497 \\
\hline $\begin{array}{c}\text { Mental accounting } \\
\text { Group xE }\end{array}$ & .03 & .13 & .13 & 1 & .722 \\
\hline
\end{tabular}

Note: $\mathrm{E}$ - empathy; B - unstandardized regression coefficient; Exp(B) - standardized regression coefficient; Wald - Wald test result; $d f$ - degrees of freedom; $p$ - statistical significance. 


\section{Discussion}

First, statistical analyses demonstrated that susceptibility to behavioral biases depends on the level of expertise in stock market investing. Second, in our sample, we observed an influence of certain personality traits on susceptibility to behavioral biases.

We found not only that frequent retail investors are susceptible to various behavioral biases when making decisions but also that the degree of susceptibility is stronger in this group than among those who are only casually engaged in investing, i.e., students (Tables 2, 3 and 4). These findings are in line with earlier studies indicating that experts are susceptible to behavioral biases (Braun \& Yaniv, 1992). Szyszka (2007) showed that a lack of understanding of the intricacies of finance and the capital market can, paradoxically, improve rationality of decisions. In his survey studies, students of fine arts and music were less susceptible to overconfidence and were more accurate in their estimates of the probability of market events than a group of stock market traders and educated investors.

Our results confirmed that the tendency to display behavioral biases is a highly automatized process, so both experts and amateurs in a given domain, and even laypeople, might be unaware of the influence these biases have on their decisions (Stephan, 1998). Moreover, there is little possibility of conscious control of these biases. Additionally, other research has shown that experts in various domains often show a strong tendency toward overconfidence when making critical decisions and sometimes intentionally use different rules of thumb to simplify the decision-making process (Roszkowski \& Grable, 2005). Furthermore, Tetlock (2005) notes that, as a way of maintaining self-esteem and professional reputation, professionals are less capable of admitting to making mistakes and correcting them than laypeople. Finally, there is some evidence on the role of age differences in decision making under risk and uncertainty because these age differences could reflect other life experiences in addition to professional expertise. In particular, it was found that age may be negatively correlated with the ability to make optimal decisions under risk and uncertainty (Dror, Katoan \& Mungur, 1998). Notably, age was not a statistically significant variable in our model, so the relative lack of rationality in decision making observed among the in- vestors compared with the students may be attributed to other factors (e.g., expert overconfidence).

We observed greater venturesomeness and marginally higher impulsivity among the students than among the investors (Table 5). This finding may be the result of the students' youth relative to the investors' age. Moreover, we can assume that students have taken fewer risks with real money thus far in their lives than investors, who work with real cash. Therefore, for the typical student participant, our study was a purely hypothetical situation, which favored making more risky and impulsive decisions as has also been observed in other research (Garvey \& Murphy, 2008).

Among the studied personality traits, only venturesomeness was statistically significant and influenced the rationality of the investors' decisions. A negative correlation was observed between venturesomeness and susceptibility to all the behavioral biases studied, i.e., the certainty effect, the sunk cost fallacy, and mental accounting (Tables 6, 7 and 8). In other words, in our sample, a higher level of venturesomeness was linked with a lower probability of behavioral biases.

To explain this result, we note that venturesomeness measures different aspects of risk-taking tendencies and is seen as a characteristic of people who are fully conscious of the risk they will take but have also fully decided to take it (Eysenck \& Eysenck 1978). It has been noted that a high level of risk aversion among stock market investors is positively correlated with various behavioral biases (e.g., the attachment effect, see: Corter \& Chen, 2006), or it results in too slow of a diversification of investment portfolios and reaction to changes in the capital market (Weller \& Tikir, 2011). Additionally, some authors stressed that the higher the risk tolerance is among market investors, the more optimal and profitable their investment decisions are (Hopfensitz \& Wranik, 2009; Sjoberg \& Engelberg 2009; Sultana \& Pardhasaradhi, 2010). However, positive correlations have been observed between venturesomeness, as measured with the IVE scale, and extraversion and openness to experience from the Big Five Model. These latter two traits predicted the effectiveness of investment fund management (Camgoz, Karan, \& Ergeneli, 2011). Venturesomeness consists of self-confidence, self-efficacy, persistence in goal pursuit, and readiness to undertake risky behaviors and seek out new challenges while considering the possible 

Alessi, S. M., \& Petry, N. M. (2003). Pathological gambling severity is associated with impulsivity in a delay discounting procedure. Behavioural Processes, 64 (3), 345-354.

Arkes, H., \& Blumer, C. (1985). The psychology of sunk cost. Organisational Behavior and Human Decision Processes, 35, 124-140.

Baddeley, M., Burke, C., Tobler, P. \& Schulz, W. (2010). Impacts of Personality on Herding in Financial Decision-Making (Working Paper No. 1006). Faculty of Economics, University of Cambridge.

Belcher, L. J. (2010). Prior perceptions, personality characteristics and portfolio preferences among fund managers: an experimental analysis. Journal of Behavioral Finance, 11 (4), 239-248.

Benos, A. (1998). Aggressiveness and survival of overconfident traders. Journal of Financial Markets, 1 (3-4), 353-383.

Bernstein, P. L. (2007). Capital Ideas Evolving. Hoboken, NJ: John Wiley \& Sons, Inc.

Borghans, L., Duckworth, A., Heckman, J., \& Weel, B. (2008). The economics and psychology of personality traits. Journal of Human Resources, 43 (4), 972-1059.

Braun, P., \& Yaniv, I. (1992). A case study of expert judgment: economists' probabilities versus baserate model forecasts. Journal of Behavioral Decision Making, 5 (3), 217-231.

Camerer, C. F., \& Johnson, E. J. (1997). The process performance paradox in expert judgment: how can experts know so much and predict so badly. In W. M. Goldstein \& R. M. Hogarth (Eds.), Research on judgment and decision making: Currents, connections, and controversies (pp. 342-364). Cambridge, UK: Cambridge University Press.

Camgoz, M., Karan, B., \& Ergeneli, A. (2011). Relationship between the Big-Five Personality and the financial performance of fund managers. Current Topics in Management, 15, 137-152.

Chira, I., Adams, M., \& Thornton, B. (2008). Behavioral bias within the decision making process. Journal of Business \& Economics Research, 6 (8), 11-20.

Connolly, T., \& Zeelenberg, M. (2002). Regret in decision making. Current Directions in Psychological Science, 11 (6), 212-216.
Corter, J., \& Chen, Y. (2006). Do investment risk tolerance attitudes predict portfolio risk? Journal of Business and Psychology, 20 (3), 369-381.

Costa, P. T., \& McCrae, R. R. (1985). The NEO Personality Inventory manual. Odessa, FL: Psychological Assessment Resources.

Coval, J., D., \& Shumway, T. (2005). Do behavioral biases affect prices? The Journal of Finance, 60 (1), $1-34$.

De Bondt, W., \& Thaler, R. (1987). Further evidence on investor overreaction and stock market seasonality. The Journal of Finance, 42 (3), 557-580.

De Bondt, W., \& Makhija, A. (1988). Throwing good money after bad? Nuclear power plant investment decisions and the relevance of sunk costs. Journal of Economic Behavior and Organization, 10 (2), 173-199.

Dror, I., Katona, M., \& Mungur, K. (1998). Age Differences in Decision Making: To Take a Risk or Not? Gerontology, 44 (2), 67-71

Durand, R. B., Newby, R., \& Sanghani, J. (2008). An Intimate Portrait of the Individual Investor. Journal of Behavioral Finance 9 (4), 193-208.

Eysenck, S. B. G., \& Eysenck, H. J. (1978). Impulsiveness and venturesomeness: Their position in a dimensional system of personality description. Psychological Reports, 43 (3), 1247-1255.

Eysenck, H. J., \& Eysenck, S. B. G. (2006). Manual for the Eysenck Personality Scales (EPS Adult) including EPQ-Revised, EPQ- Short Scale, IVE Questionnaire. London, UK: Hodder and Stoughton Educational.

Fama, E. F. (1970). Efficient capital markets: A review of theory and empirical work. Journal of Finance, 25 (2), 383-417.

Fama, E. F. (1991). Efficient capital markets II. Journal of Finance, 46 (5), 1575-1617.

Freedman, D. (2009). Statistical Models: Theory and Practice ( $2^{\text {nd }}$ ed.). Cambridge, UK: Cambridge University Press.

Friedman, D., Pommerenke, K., Lukose, R., Milam, G., \& Huberman, B. A. (2007). Searching for the sunk cost fallacy. Experimental Economics, 10 (1), 79-104.

Garvey, R., \& Murphy, A. (2008). Are professional traders too slow to realize their losses? Financial Analysts Journal, 60 (4), 35-43. 
Haigh, M., \& List, J. (2005). Do professional traders exhibit myopic loss aversion? An experimental analysis. The Journal of Finance, 60 (1), 523-534.

Hayaki, J., Anderson, B., \& Stein, M. (2006). Sexual risk behaviors among substance users: relationship to impulsivity. Psychology of Addictive Behaviors, 20 (3), 328-332.

Hopfensitz, A., \& Wranik, T. (2009). How to Adapt to Changing Markets: Experience and Personality in a Repeated Investment Game (Working Paper No. 122). Toulouse School of Economics.

Jadlow, J., \& Mowen, J. (2010). Comparing the Traits of Stock Market Investors and Gamblers. Journal of Behavioral Finance, 11 (2), 67-81.

Kahneman, D., \& Tversky, A. (1973). On the psychology of prediction. Psychological Review, 80 (4), 237-251.

Kahneman, D., \& Tversky, A. (1979). Prospect theory: An analysis of decisions under risk. Economoterica, 47 (2), 263-292.

Kahneman, D., \& Tversky, A. (1984). Choices, values and frames. American Psychologist, 39 (4), 341 350.

Kahneman, D. (2012). Thinking fast and slow. New York, NY: Penguin Books Ltd.

Krems, J., \& Zierer, C. (1994). Are experts immune to cognitive bias? Dependence of "confirmation bias" on specialist knowledge. Zeitschrift für experimentelle und angewandte Psychologie, 41 (1), 98-115.

Markowitz, H. M. (1952). Portfolio selection. Journal of finance, 7 (1), 77-91.

Mayfield, C., Perdue, G., \& Wooten, K. (2008). Investment management and personality type. Financial Services Review, 17 (3), 219-236.

McAfee, R. P., Mialon, H. M., \& Mialon, S. H. (2010). Do sunk costs matter? Economic Inquiry, 48 (2), 323-336.

Mishra, S., Lalumiere, M. L., \& Williams, R. J. (2010). Gambling as a form of risk-taking: individual differences in personality, risk-accepting attitudes, and behavioral preferences for risk. Personality and Individual Differences 49 (6), 616-621.

Odean, T. (1998). Are investors reluctant to realize their losses. Journal of Finance, 53 (5), 1775-1798

Pompian, M., \& Longo, J. (2004). A new paradigm for practical application of behavioral finance: creat- ing investment programs based on personality type and gender to produce better investment outcomes. The Journal of Wealth Management, 7 (2), 9-15.

Roszkowski, M., \& Grable, J. (2005). Estimating risk tolerance: the degree of accuracy and the paramorphic representations of the estimate. Financial Counseling and Planning, 16 (2), 29-47.

Rzeszutek, M., Czerwonka, M. (2011). Analiza zachowań inwestycyjnych inwestorów giełdowych i studentów kierunków ekonomicznych i humanistycznych z perspektywy finansów behawioralnych [Analysis of investment behawior of stock market investors and economics and humanities students from the perspective of behavioral finance]. Studia i Prace Kolegium Zarzadzania i Finansów Szkoły Głównej Handlowej, 107, 28-44.

Sadi, R., Asl, H. G., Rostami, M., Gholipour, A., \& Gholipour, F. (2011). Behavioral finance: the explanation of investors' personality and perceptual biases effects on financial decisions. Intemational Joumal of Economics and Finance, 3 (5), 234-241.

Sjoberg, L., \& Engelberg, E. (2009). Attitudes to economic risk taking, sensation seeking and values of business students specializing in finance. Journal of Behavioral Finance, 10 (1), 33-43.

Stephan, E. (1998, June). Heuristics and biases in decision making: the role of incentives, ability, and expertise. Paper presented at research Seminar held at the Erasmus University Rotterdam.

Sultana, S. T., \& Pardhasaradhi S. (2010). An empirical investigation of the relation between risk tolerance and socioeconomic characteristics of individual investors. Advances in Management, 4 (10), 60-66.

Szyszka, A. (2007). Wycena papierów wartościowych na rynku kapitałowym $w$ świetle finansów behawioralnych [A behavioral finanse perspective on valuation of securities on the capital market]. Poznań: Wydawnictwo Akademii Ekonomicznej w Poznaniu.

Szyszka, A., Zielonka, P. (2007). The Disposition Effect Demonstrated on IPO Trading Volume. Journal of Behavioral Finance, 4 (3), 40-48.

Szyszka, A. (2010). Preferences and belief based models. In. H. K. Baker \& J. Nofsinger (Eds.), Behavioral Finance: Investors, Corporations, and Markets, (pp. 351 - 372). Hoboken, NJ: J. Wiley \& Sons. 
Tetlock, P. (2005). Expert Political Judgment: How Good Is It? How Can We Know? Princeton, NJ: Princeton University Press.

Thaler, R. (1999). Mental accounting matters. Journal of Behavioral Decision Making, 12 (3), 183-206.

Todd, P. M., \& Gigerenzer, G. (2003). Bounding rationality to the world. Journal of Economic Psychology, 24 (2), 143-165.

Tyszka, T., \& Zielonka, P. (2002). Expert judgments: financial analysts vs. weather forecasters. Journal of Psychology and Financial Markets, 3 (3), 152-160.

Von Neumann, J., \& Morgenstern, O. (1944). Theory of games and economic behavior. Princeton, NJ: Princeton University Press.

Verma, R., Baklaci, H., \& Soydemir, G. (2008). The impact of rational and irrational sentiments of individual and institutional investors on DJIA and S\&P500 index returns. Applied Financial Economics, 18 (16), 1303-1317.

Weller, J. A., \& Tikir, A. (2011). Predicting domainspecific risk taking with the HEXACO personality structure. Journal of Behavioral Decision Making, 24 (2), 180-201.

Winnett, A., \& Lewis, A. (1994). Household accounts, mental accounts and savings behaviour: Some old economics rediscovered? Journal of Economic Psychology, 16 (4), $431-448$. 


\section{Appendix}

\section{Appendix 1. Exercise measuring susceptibility to the certainty effect}

\section{EXERCISE 1}

Please imagine that you must choose between options A and B. (Please circle the preferred option):

A. A lottery in which:

- You have an $80 \%$ probability of winning 4,000 PLN.

- You have a $20 \%$ probability of not winning anything.

B. A certain win of 3,000 PLN.

Now, please choose between options C and D:

C. A lottery in which you could win:

- 4,000 PLN with a probability of $20 \%$.

- Nothing, with a probability of $80 \%$.

D. A second lottery in which you could win:

- 3,000PLN with a probability of $25 \%$.

- Nothing, with a probability of $75 \%$.

\section{Appendix 2. Exercise measuring susceptibility to the sunk cost fallacy}

\section{EXERCISE 2}

As the president of a large aviation company, you have invested 10 million dollars in a development project. Its goal was to build an airplane that would quickly cover the distance between Europe and the USA. When your project is $90 \%$ complete, a rival company announces that it is introducing an identical plane onto the market, which, as it turns out, is much more economical to use than yours. In this situation, would you invest the final $10 \%$ of the costs to complete the project (option A), or would you instead decide to immediately abandon it (option B)? (Please circle the option you would choose).

\section{Appendix 3. Exercise measuring susceptibility to mental accounting}

\section{EXERCISE 3}

Please imagine the following two situations, A and B, and circle the behavior that you would choose in each: A. You have decided to go see a movie, and you have bought a ticket for 20 PLN. After entering the cin- ema, you discover that you have lost the ticket. You do, however, have a 20 PLN bill in your pocket. Do you spend another 20 PLN to buy another ticket, or do you decide not to see the movie?

B. Now, please imagine that you have decided to go see a movie but have not yet bought a ticket. As you leave your home, you take two 20 PLN bills with you. After entering the cinema, you discover that you have lost 20 PLN. In this situation, do you spend the other 20 PLN to buy a ticket, or do you decide not to see the movie? 
